\title{
SENTIDOS DO USO DA TÉCNICA DO BALÉ CLÁSSICO SOB A ÓTI- CA DE DIRETORES DE ESCOLAS TÉCNICAS PARTICULARES DE DANÇA DO RIO DE JANEIRO
}

\author{
Heloisa Suzano Almeida \\ Universidade Candido Mendes, Rio de Janeiro, Rio de Janeiro, Brasil \\ Monique Ribeiro Assis \\ Universidade Estadual do Rio de Janeiro, Rio de Janeiro, Rio de Janeiro, Brasil
}

\begin{abstract}
Resumo
O presente estudo objetiva verificar os sentidos da utilização da técnica do balé clássico no atual mercado de trabalho da dança profissional carioca sob a ótica de diretores de escolas técnicas privadas de dança da cidade do Rio de Janeiro. Para a coleta de dados, foram realizadas entrevistas semiestruturadas. A amostra foi composta por quatro diretores de dança. Os discursos foram interpretados usando o método de análise do discurso, proposto por Eni Orlandi. Verificou-se que os diretores mantêm os preceitos fundantes da técnica na formação de seus bailarinos, mas a colocam em um novo lugar, que dialoga com outras técnicas e métodos do universo da dança cênica contemporânea.
\end{abstract}

Palavras-chave: Dança. Técnica do balé. Análise do discurso. Formação profissional.

\section{Introdução}

Para se dançar o balé clássico é imprescindível que se aprenda, domine e pratique a sua técnica. Porém, a recíproca não é verdadeira, pois, ao aprender esta técnica, não será imperioso que se dance o balé clássico. É possível utilizar a técnica do balé clássico para outros fins, como: dançar outras danças, trabalhar a consciência corporal, melhorar seu desempenho em algum esporte, entre outras possibilidades. Portanto, sem o risco de incorrer em uma generalização vazia, pode-se dizer que a técnica do balé clássico tornou-se, ao longo da sua história, autônoma em relação à dança que a gerou.

A formação completa do bailarino com a técnica do balé clássico é longa e sólida e há um consenso na literatura de que um estudante leva em torno de oito a dez anos para se formar (ACHCAR, 1998; ARAGÃO, 2006; MALANGA, 1995; MENDONÇA, 2013; TARASOV, 1985). Atualmente na cidade do Rio de Janeiro, além dos cursos livres de dança, existem seis escolas que oferecem o ensino técnico profissionalizante em dança ${ }^{1}$, sendo duas es-

\footnotetext{
${ }^{1}$ Disponível em: http://www.faq.inf.br/educacao-profissional/escolas-tecnicas-no-rj-cursos-tecnicospresenciais-e-a-distancia/. Acesso em: 27 jan. 2016.
} 
colas públicas $^{2}$ e quatro particulares. A técnica do balé clássico é oferecida em todas elas e, na maioria das vezes, com uma carga horária e nível de exigência superiores às outras práticas.

A técnica do balé clássico vem se desenvolvendo há mais de 300 anos e permeia a formação e o treinamento diário de grande parte dos bailarinos profissionais atuais. $\mathrm{O}$ bailarino utiliza seu corpo como instrumento e, assim como os atletas, precisa de um treinamento árduo, contínuo e singular. O corpo é o primeiro e mais natural objeto técnico do homem, e as técnicas são maneiras de se servir dele (MAUSS, 1974). A técnica do balé clássico trabalha, segundo Moreira (2014, p. 90), "força, resistência, postura, equilíbrio, alongamento, flexibilidade, graciosidade e elegância", valências imprescindíveis para estes profissionais.

Ocorre que, principalmente depois do desenvolvimento da dança contemporânea, a partir da década de 1960 pelas mãos de Merce Cunninghan nos Estados Unidos e Pina Baush na Alemanha, o mercado da dança profissional diversificou-se. Conforme Buarque (2014), a maior parte das companhias profissionais de dança carioca atualmente trabalha com a dança contemporânea, que expressa uma estética diferenciada do balé clássico. Em concordância com Buarque, Puoli (2010, p. 51), em uma análise mais mercadológica, afirma que: "O nicho de dança clássica no Brasil é restrito e os projetos de dança contemporânea encontram terreno mais fértil para se instalarem e permanecerem por serem mais arrojados e modernos".

A prevalência da dança contemporânea sobre o balé clássico no cenário carioca pode ser evidenciada a partir da análise dos 18 projetos aprovados para a área de dança no Programa de Fomento à Cultura ${ }^{3}$ de 2015. Entre esses 18 projetos, 16 eram relacionados com a dança contemporânea (festivais, companhias, solos), um estava ligado à dança moderna e apenas um destinava-se ao balé clássico, e era para a construção de um site.

A intenção deste estudo é investigar os sentidos dessa formação na atualidade e entender como estão sendo preparados os futuros profissionais da dança carioca a partir da perspectiva dos diretores de escolas técnicas particulares de dança cariocas, levando-se em conta o mercado profissional da dança atual.

Importante ressaltar que o objetivo deste trabalho não é levantar debates sobre a atividade artística/estética do balé clássico e sim entender como a sua técnica permanece depois de mais de três séculos como uma formação corporal, sob a ótica desses formadores de profissionais na cidade do Rio de Janeiro. Pensar a técnica do balé clássico, isoladamente de sua dança, amplia as possibilidades de pesquisa na dança e pode contribuir para refinar o olhar sobre a formação dos atuais e futuros bailarinos profissionais brasileiros:

Ao nos depararmos com a construção da história da dança cênica, percebemos que o corpo que dança nas diferentes épocas foi adaptado por padrões estéticos que serviam às construções técnicas fundamentadas nos valores e pensamentos vigentes no meio sócio cultural (TORRES, 2008, p. 1).

\footnotetext{
2 Processo seletivo obrigatório por aptidão física, técnica e artística ou por sorteio.

3 Programa da Secretaria Municipal de Cultura da cidade do Rio de Janeiro, que tem como objetivo fomentar a produção artística da cidade. Segundo seu site, "trata-se do maior e mais abrangente edital público do país", o qual designou três milhões de reais para o patrocínio à dança em 2015. Disponível em: 〈http://www.rio.rj.gov.br/dlstatic/10112/5481854/4143460/PublicacaoResultados_2015.pdf>. Acesso em 6 mar. 2016.
} 
O balé clássico e sua técnica

O balé clássico é uma forma de dança que nasceu na Itália no século XV, foi levada para a França no século XVI e lá codificada no século XVII. Depois foi difundida no Ocidente a partir do século XVIII e refinada, como conhecemos hoje, no século XIX.

O nascimento do balé clássico se confunde com o processo civilizatório ocidental, que consistiu na interiorização individual das proibições, no fortalecimento dos mecanismos de autocontrole exercidos sobre as pulsões e emoções e que fez passar do condicionamento social ao autocondicionamento no Ocidente. A nobreza cortesã da França dos séculos XVII e XVIII formou o elenco básico de modelos de conduta social ocidental da época (ELIAS,1993). É nessa corte, e coincidentemente em seu primeiro ano de poder pessoal, que o rei Luís XIV criou a Academia Real de Dança em 1661, com o intuito de imobilizar a dança da época em regras (BOURCIER, 2001). Posteriormente, o rei solicitou ao seu mestre de dança, Charles-Louis-Pierre de Beauchamps, que sistematizasse a técnica do balé clássico. O mestre então estabeleceu as cinco posições dos pés e designou termos em francês para os passos. Beauchamps criou um sistema de disposições corpóreas que possibilitou sua reprodução e que são observadas como a base fundamental da técnica do balé clássico até os dias atuais (SOUZA, 2009).

Após este primeiro momento, a técnica do balé clássico passou por várias fases, nas quais foram acrescentados novos movimentos. No século das Luzes, o balé clássico teve como estímulo uma nova plateia, a burguesia, que buscava ascender socialmente. Nesse período, a aristocracia já vinha sofrendo uma pressão muito grande da burguesia e ir ao teatro ver os balés aumentava o prestígio social desta classe (ELIAS, 1993). Para agradar esse novo público, os mestres de dança da época iniciaram algumas modificações na técnica do balé clássico, como o incremento de novos e rebuscados passos.

No século seguinte, após a Revolução Francesa, com o surgimento do balé romântico, um dos momentos mais importantes da história da dança cênica ocidental, a técnica do balé clássico se aperfeiçoou e surgiu com um novo recurso técnico que permanece até os dias atuais, a dança sobre pontas (PEREIRA, 2006). Na segunda metade do século XIX, o balé clássico migrou para a Rússia, associado ao projeto de ocidentalização do país. Lá a técnica do balé clássico foi redefinida por vários mestres de balé franceses, italianos e dinamarqueses, culminando com uma nova geração de bailarinos com corpos esculpidos, movimentos dóceis e fluidos que realçavam a flexibilidade (HOMANS, 2012). Um pequeno grupo desses bailarinos russos mudou-se para a França no começo do século XX e levou o balé clássico e sua técnica a um novo patamar que culminou com o desabrochar da dança moderna.

Nesse estágio, as vanguardas modernistas começaram a propor novas estéticas para a dança cênica, às vezes até negando alguns de seus elementos tradicionais, como a sapatilha de ponta, os vestidos de tule e os temas etéreos e platônicos que ainda permeavam os espetáculos (GONÇALVES, 2014). A dança moderna aproximava a dança do mundo real, relacionando arte e vida, porém não havia muita dúvida sobre o que constituía o universo da dança cênica profissional e a técnica do balé clássico seguia como o treinamento fundamental para todo e qualquer bailarino profissional. Porém, após os anos 1950, uma mudança conceitual friccionou o mundo da arte. Surgiu, então, a dança contemporânea, que não se enquadrava nas classificações tradicionais de balé clássico ou de dança moderna, e com ela novas demandas, incluindo a preparação e a formação do bailarino (DANTAS, 2005). A técnica do balé clássico passou a ser questionada e, desde então, esse tema vem sendo abordado de forma polêmica no mundo da dança.

Para entender melhor essa questão da preparação e formação do bailarino, é importante retornar às cartas patentes do rei Luís XIV para o estabelecimento da primeira escola oficial de dança do mundo ocidental, a Academia Real de Dança, a qual foi criada com o intuito de 
preservar a forma de dançar da época. Nessas cartas, traduzidas por Teixeira (2012), é possível identificar essa intenção:

Luís, pela graça de Deus, Rei da França e de Navarra, a todos os presentes e aos que virão, nossa saudação. Apesar de a Dança ter sido sempre reconhecida como uma das artes das mais honestas e necessárias para a formação do corpo e lhe dar as primeiras e mais naturais disposições para todo tipo de exercícios, como aqueles das armas, entre outros, e sendo, em consequência, uma das mais vantajosas e úteis aos nossos Nobres, bem como aos demais que têm a honra de se aproximar de nossa pessoa, não apenas em tempo de guerra, em nossos exércitos, mas também em tempo de paz, no entretenimento de nossos Balés. Entretanto, durante as desordens e a confusão das últimas guerras, foi introduzida nesta Arte, como em todas as outras, uma grande quantidade de abusos capazes de conduzi-la à ruína irreparável. Várias pessoas, por mais ignorantes e inábeis que se mostrassem na Arte da Dança, intrometeram-se para apresentá-la em público, sendo de surpreender que a pequena quantidade daqueles capazes de ensinar essa arte, por meio do estudo e da prática, tenha resistido tanto tempo aos principais defeitos com que a quantidade infinita dos ignorantes se esforçavam para desfigurá-la e corrompê-la entre a maioria dos cavalheiros. Isso faz com que, em nossa Corte e séquito, vejamos poucas pessoas capazes de ingressar em nossos $\mathrm{Ba}-$ lés e outros divertimentos de Dança, qualquer que seja nossa intenção para tanto (LUÍS XIV apud TEIXEIRA, 2012, p. 2).

No mesmo documento, Luís XIV estabeleceu um grupo de 13 veteranos que restabeleceriam a arte da dança na sua perfeição original. Esses veteranos se reuniriam uma vez por mês para:

[...] lá conferir entre eles sobre as atividades da Dança, opinar e deliberar a respeito dos meios para aperfeiçoar essa Arte, corrigir os abusos e defeitos que possam se introduzir nela, manter e reger esta Academia segundo e conforme os Estatutos e Regulamentos em anexo, reunidos sob a contra-cancela de nossa Chancelaria, e queremos que eles sejam guardados e observados nas suas formas e teores. Fazemos a expressa proibição a todas as pessoas, de qualquer condição, e sob pena de multa para os contraventores, podendo ser maiores segundo o caso (LUÍS XIV, apud TEIXEIRA, 2012, p. 3).

Esse início austero na formação em dança permeou e ainda permeia a dança profissional, que carrega toda essa bagagem. Conforme Oliveira (2013), atualmente parte de profissionais da área da dança afirma que o treinamento com a técnica do balé clássico representa uma base para todo e qualquer desempenho refinado na dança. Por outro lado, outra parte reconhece o valor da técnica, mas não a considera o único meio para capacitar um bailarino. Rocha (2014, p. 39) parece ter encerrado esta controvérsia ao considerar esse embate um tanto ultrapassado: "quem ousará repetir bobices tão festejadas por aí: de um lado os imperialistas dizendo 'ballet é a base de tudo'; de outro, os relativistas com suas máximas 'ballet não muda'[...] Falsos problemas". Para a autora, o balé não é a base, muda sempre e o problema talvez esteja no ensino.

No Brasil, a criação da primeira escola oficial de bailados, a atual Escola de Dança, Artes e Técnicas do Theatro Municipal Maria Olenewa, em 1927, foi "o primeiro passo, fundamental, para a construção de uma história, de uma tradição de dança no país" (PEREIRA, 2003, p. 91). Desde então, o balé clássico e sua técnica vêm se disseminando por terras brasileiras. Dessa escola surgiu o Corpo de Baile do Theatro Municipal do Rio de Janeiro, sendo que essas duas instituições cariocas foram e são ainda subsidiadas pelo estado do Rio de Ja- 
neiro. A partir desse impulso inicial, outros estados criaram também suas companhias de balé e escolas de dança sustentadas pelo dinheiro público. Teixeira (2011) mapeou as companhias brasileiras, apontando que, dentre elas, a que mantém vínculo com o repertório clássico é o Ballet do Theatro Municipal do Rio de Janeiro. Todas recebem coreógrafos nacionais e estrangeiros das várias linguagens da dança clássica, moderna e contemporânea. São elas, por ordem cronológica:

1. Ballet do Theatro Municipal do Rio de Janeiro (RJ, 1936); 2. Balé da Cidade de São Paulo (SP, 1968); 3. Balé Teatro Guaíra (PR, 1969); 4. Cia. de Dança Palácio das Artes (MG, 1971); 5. Balé do Teatro Castro Alves (BA, 1981); 6. Balé da Cidade de São José do Rio Preto (SP, 1987); 7. Companhia de Ballet da Cidade de Niterói (RJ, 1992); 8. Balé da Cidade de Teresina (PI, 1993); 9. Companhia Municipal de Dança de Caxias do Sul (RS, 1997); 10. Companhia de Dança do Amazonas (AM, 1998); 11. Balé do Estado de Goiás (GO, 1999); 12. Balé da Cidade de Natal (RN, 2002); 13. Balé da Cidade de Taubaté (SP, 2006); 14. Companhia Municipal de Dança de Belém (PA, 2006); 15. Bailare - Cia. Municipal de Dança (Vacaria/RS, 2008); 16. São Paulo Cia. de Dança (SP, 2008); 17. Corpo Estável do Polytheama (Jundiaí/SP, 2011) (TEIXEIRA, 2011, p. 3).

\section{Procedimentos metodológicos}

Para atender ao objetivo proposto pelo estudo, optou-se pela utilização de uma pesquisa descritiva com abordagem qualitativa, que se caracterizou por buscar os dados diretamente na fonte de origem por meio de entrevistas semiestruturadas. Essas entrevistas são úteis por favorecer "[...] não só a descrição dos fenômenos sociais, mas também sua explicação e a compreensão de sua totalidade, tanto dentro de sua situação específica como de sua situação de dimensões maiores" (TRIVIÑOS, 1987, p.152)

Das seis escolas que oferecem o ensino técnico em dança na cidade do Rio de Janeiro, foram convidados os diretores das quatro escolas técnicas de dança particulares da cidade, das quais duas estão situadas na zona norte e duas na zona sul da cidade. A escolha das escolas particulares se deu em função de não terem um processo seletivo rigoroso nem vagas limitadas e oferecerem bolsas de estudo para alunos com potencial para a dança. Essas escolas têm grande relevância para a dança carioca e delas saíram vários bailarinos para o mercado de trabalho. Importante também destacar que essas escolas têm entre 30 e 45 anos de existência, o que dá a esses diretores uma representação significativa no cenário da dança da cidade. Todos os quatro diretores se disponibilizaram. Após o aceite, foram definidos data, local e horário apropriados para a realização das entrevistas individuais. Todas as diretrizes da pesquisa, incluindo a leitura do Termo de Consentimento Livre e Esclarecido (TCLE), foram feitas. As entrevistas ocorreram entre novembro de 2015 e janeiro de 2016.

Finalizada essa etapa, o material coletado foi transcrito para análise. Os dados foram analisados e interpretados a partir do método de análise do discurso de Eni Orlandi (2013). A escolha desta técnica de análise de dados pretendeu relacionar os sujeitos entrevistados com outros sujeitos, com os sentidos, com a história, visando compreender como esse treinamento secular se apresenta na atual conjuntura (ORLANDI, 2013). Após a transcrição na íntegra das entrevistas gravadas, o texto foi analisado conforme a autora propõe, passando da superfície linguística para o objeto discursivo e depois para o processo discursivo.

A pesquisa obedeceu aos padrões éticos exigidos pela Resolução 196/96, do Conselho Nacional de Saúde (CNS), sobre pesquisa com seres humanos, e foi aprovada pelo Comitê de Ética do Hospital Universitário Pedro Ernesto/ UERJ. Foi aprovada em 10 de outubro de 2015, sob o protocolo de número: 49210115.9.0000.5259. 


\section{Resultados e discussão}

A técnica do balé clássico em sua gênese, como já visto anteriormente, foi descrita na carta da criação da Academia Real de Dança como primordial para todos o tipos de exercícios da época (TEIXEIRA, 2012). Em algumas falas dos entrevistados ${ }^{4}$, pode-se reconhecer pensamento semelhante, quando eles foram perguntados sobre a importância da técnica do balé para os futuros bailarinos em relação às outras técnicas:

A vontade de dançar é grande, então eles têm o balé clássico como primeiro caminho, mas nem sempre é o balé que vai realizá-los, mas eles entram primeiro no balé e depois vão para outros. (DE 1)

Acho que ele tem sim (que fazer balé) [...] para que ele possa conviver com outras danças [...] agora o balé vai dar a possibilidade dele trabalhar melhor, dele poder entender o que ele está fazendo. (DE 2)

É indispensável. (DE 4)

O discurso é o lugar em que se pode compreender como a língua produz sentidos por/para os sujeitos. Quando nascemos, os discursos já estão em processo e as condições e os locais de produção compreendem os sujeitos e a situação. No sentido amplo, essas condições de produção incluem o contexto sócio-histórico e ideológico (ORLANDI, 2013). No final do século XVII, dentro da corte francesa, ser treinado pela técnica do balé clássico distinguia um nobre em relação ao outro, e ter o domínio da técnica do balé clássico era quase uma experiência mítica, no sentido designado por Ansart (1978), pois era uma experiência na qual o imaginário era vivido cotidianamente tanto na relação dos homens consigo mesmos como com o mundo e com os outros. A corte de Luís XIV não mais existe, contudo, pode-se perceber nas falas que essa distinção da técnica do balé clássico ainda persiste e coincide com achados de outros autores. Nos cinco livros escritos sobre história da dança no Brasil até 1999, o tratamento dado ao balé clássico mereceu destaque em todos e era considerado superior a outras formas de dança (FERREIRA, 2008). Nos exemplos, “ [...] eles têm o balé clássico como primeiro caminho [...]" ou "Acho que ele tem sim (que fazer balé) [...] para que possa conviver com as outras danças [...]" ou simplesmente "Indispensável.", verifica-se que existe uma razão histórica e ideológica nas falas dos entrevistados influenciada por dizeres anteriores. É o que Orlandi (2013) chama de interdiscurso ou memória discursiva que disponibiliza dizeres que vão afetar o modo como os sujeitos significam uma determinada mensagem.

Entretanto, em vários momentos, foi possível perceber uma tentativa de mudança de padrão em relação à preponderância da técnica do balé clássico como treinamento prevalente pelos entrevistados. Ei-los:

[...] o que a gente orienta é que eles tenham um pensamento mais aberto, porque antigamente eles eram muito bitolados. [...] Então a gente convida eventualmente alguns professores pra que eles possam conhecer essas outras linguagens. [...] eles não tem que ficar presos ao balé clássico. (DE 1)

[...] não é um balé [...] focado no balé do século retrasado. Agora dentro do curso de balé ele (bailarino) faz (aula de dança contemporânea) uma vez

\footnotetext{
${ }^{4}$ Neste estudo, os entrevistados serão designados pelas siglas DE (diretores de escolas), seguidas de números para que suas identidades permaneçam ocultas.
} 
por semana [...] E aí ele (o bailarino) vai ter contato com outra possibilidade de dança, ele pode ir sem sapatilha, ele vai como ele quiser, ele vai ter e vivenciar outra possibilidade de dança. (DE 2)

[...] na verdade a gente vai ver o balé como instrumento para melhor dançar e localizar outras linguagens. (DE 3)

Eles (os futuros bailarinos) deveriam usar todas as técnicas de dança que fariam muito bem a eles. Eles deveriam poder usar o corpo em várias formas. [...] Para que seu corpo possa sentir as diferenças, pois ele fica mais preparado (quando faz outras técnicas). Para qualquer coisa que vier ele estar pronto. Ele não se limita a uma técnica. (DE 4)

[...] a técnica do balé na verdade é estruturante, [...] nos dá elementos para compreender o vocabulário, a história da dança, e que ela vai desenvolver determinadas habilidades. (DE 3)

É preciso escutar o não dito naquilo que é dito, pois só uma parte do que o sujeito diz é acessível a ele próprio (ORLANDI, 2013). Observa-se que as falas acima estão atreladas ao treinamento do balé clássico como alicerce para a formação do bailarino contemporâneo quando dizem: "Então a gente convida eventualmente alguns professores para que eles possam conhecer essas outras linguagens [...]" ou "E aí ele vai ter contato com outra possibilidade de dança." Ou ainda "[...] eles não têm que ficar presos ao balé clássico".

Mas, ao mesmo tempo, é possível sentir uma tentativa de apontar novos caminhos, como em: "Eles deveriam poder usar o corpo em várias formas" ou "[...] a gente vai ver o balé como instrumento para melhor dançar e localizar outras linguagens". Esses dizeres coincidem com os achados de autores contemporâneos que constataram também que, até o final do século XX, existia uma concordância entre os profissionais da área de que o balé clássico seria uma dança-mãe, mas os autores perceberam que existe hoje uma mudança em relação a essa ideia por parte de bailarinos contemporâneos (MONTE; NASCIMENTO, 2008). Importante ressaltar que o termo balé. citado nos dizeres, se refere ao treinamento com a técnica do balé clássico.

Em uma das falas, pode-se identificar que existe um olhar que aponta para o sentido de alicerce que a técnica da dança balé clássico desenvolve: “[...] a técnica do balé na verdade é estruturante, $[\ldots]$ nos dá elementos para compreender o vocabulário, a história da dança, e que ela vai desenvolver determinadas habilidades". Apesar de pouco articulado com os outros dizeres, mostra a emergência das novas possibilidades de entendimento da utilização da técnica do balé clássico no mundo da dança contemporânea. No discurso, é difícil traçar limites entre o que está na memória, nomeado como parafrástico por Orlandi (2003), e o atual, polissêmico (idem), que joga com o equívoco. Nos casos dos dizeres acima, foi possível depreender que, ao mesmo tempo em que existe algo que mantém, "Agora dentro do curso de balé, existe um impulso direcionando para o novo, "[...] ele vai ter que vivenciar outra possibilidade de dança".

Em relação aos alunos, os entrevistados reconheceram que existe uma mudança na procura por outras técnicas em suas escolas e na forma como eles estimulam novos caminhos, muito pelas questões mercadológicas e pelas atribulações da vida contemporânea, como se pode observar nas falas abaixo:

Eu percebo, eu acho que está havendo isso (uma mudança na procura), acho que hoje em dia os alunos estão tendo uma cabeça um pouquinho mais aberta e acho que até em função de tanta mudança, com a cultura da dança mudando bastante, com outros tipos de cia contemporâneas, de outros tipos de 
dança, vem espetáculos de fora. A gente sempre incentiva as pessoas a verem tudo. Então começam a ver outros trabalhos e tem pensamentos diferentes. [...] hoje em dia eu acredito que a gente forme aluno pra qualquer tipo de cia, inclusive para trabalhos com musicais, sabe? (DE 1)

[...] nós trabalhamos sim com jazz muito voltado pra uma nova ideia do mercado que são os musicais. (DE 2)

É porque eles têm menos tempo, eles são solicitados de tal forma pra tantas coisas diversificadas que é difícil de se concentrar [...]. Eles têm outros desafios, mas ao mesmo tempo mais insegurança do futuro deles, então eles jogam em vários setores, então há uma dedicação menor [...]. (DE 4)

Os fatores mercadológicos e as atribulações da vida atual podem justificar algumas mudanças no pensamento dos diretores entrevistados, pois, como vivem desse universo, se faz necessária uma adaptação do seu negócio. Essa relação entre o simbólico, que mantém o balé clássico como primeira escolha, e o mundo real, que se transforma continuamente e traz outras possibilidades de dança, permite esse deslocamento, essa ruptura para novas possibilidades dentro das escolas. Orlandi (2013) explica bem essa relação quando diz:

Entre o jogo e a regra, a necessidade e o acaso, no confronto do mundo e da linguagem, entre o sedimentado e o a se realizar, na experiência e na história, na relação tensa do simbólico com o real e o imaginário, o sujeito e o sentido se repetem e se deslocam (p. 53).

A dança pode ser investigada e percebida por diferentes aspectos de análise, que podem conferir diversos sentidos e significados, e se configura como um campo com leis próprias, demonstrando "[...] seu potencial enquanto fenômeno social no processo de renovação, transformação e significação da sociedade" (SILVA, MEDEIROS e MARCHI, 2012, p. 466)

Percebeu-se, nas falas analisadas, que o pensamento mais antigo, e que perdurou por mais de dois séculos, sobre o treinamento do balé clássico como suporte para toda e qualquer dança vem se transformando. Mesmo para os formadores que acreditam na formação de bailarinos com um enfoque principal na técnica do balé clássico, em seus discursos, já não a evidenciam mais como única: "É nesse jogo entre paráfrase e polissemia, entre o mesmo e o diferente, entre o já-dito e o a se dizer que os sujeitos e os sentidos se movimentam, fazem seus percursos, (se) significam" (ORLANDI, 2013, p. 36). Preserva-se o prestígio, indicando-a como primeira técnica de treinamento, mas permite-se uma interpenetração com outras técnicas de dança associadas para que os bailarinos possam se adequar às demandas da dança atual. Períodos de transição como este proporcionam uma oportunidade para se refletir, pois os padrões novos ainda não surgiram, mas os padrões antigos já foram contestados (ELIAS, 1993).

\section{Considerações finais}

Após a análise das entrevistas, foi possível constatar que existe uma mudança de olhar para a técnica do balé clássico. Todos os diretores de escolas técnicas particulares de dança, que são os principais formadores cariocas, enxergam a técnica do balé clássico como uma importante ferramenta para os bailarinos que eles se propõem a formar e, ao mesmo tempo, estão disponíveis a acompanhar as transformações inexoráveis da dança profissional, que tende a ser cada vez mais híbrida.

Voltando às perguntas iniciais sobre os sentidos dessa formação na atualidade e como se deve preparar os futuros profissionais que pretendem servir ao mercado da dança carioca 
atual, pôde-se inferir que os sentidos estão se alterando. Os diretores das escolas técnicas mantêm os preceitos fundantes da técnica do balé clássico, mas a colocam em um novo lugar. Um lugar de consciência, de instrumentalização corporal, que agrega valor para os bailarinos contemporâneos e, ao mesmo tempo, dialoga com outras técnicas e métodos do universo da dança cênica. Menos uma dança-mãe e mais uma dança-irmã mais velha. Como disse Arrieta (apud Santos, 2014, p. 79): “A técnica clássica, no decorrer da história, é a que mais teve oportunidade de se desenvolver, tornando-se, portanto, um legado de indiscutível importância para todo o conjunto de danças que coexistem na contemporaneidade."

Importante que novos estudos sobre o balé clássico e sua técnica sejam fomentados para que outros caminhos possam ser percorridos. Como continuidade, sugere-se investigar, pelo olhar de jovens bailarinos profissionais, como eles percebem e sentem esta técnica na contemporaneidade.

A técnica do balé clássico foi sistematizada em uma sociedade aristocrática, patrocinada por um rei absolutista, em um momento que Elias (1993) descreveu como de intensa regulação dos impulsos do início do processo civilizatório ocidental. Zygmunt Bauman (2001) utiliza a metáfora "modernidade sólida" para essa época sem ambivalências, na qual tudo deveria ser conhecido, categorizado e controlado. O balé clássico e sua técnica são, por conseguinte, impregnados dessa solidez.

Já a sociedade atual vive em um mundo que se transforma a uma velocidade incrível, e que difere em estrutura de todas as mudanças precedentes (ELIAS, 1993). Bauman (2001) considera adequadas, para captar a presente fase, as metáforas "liquidez" ou "fluidez". A dança atual não ficou de fora e vem acompanhando essas transformações, flexibilizando-se e liquidificando-se.

Portanto, a técnica do balé clássico, que já se tornou autônoma em relação à dança que a gerou, não precisa carregar o momento histórico que a constituiu. Com a sua solidez, pode ser capaz de auxiliar os futuros bailarinos contemporâneos em suas ancoragens corpóreas para essa dança líquida atual e, lado a lado com outras técnicas e métodos, seguir contribuindo para a dança, para a educação do corpo e para quem mais dela quiser usufruir.

\title{
MEANINGS OF USING CLASSICAL BALLET TECHNIQUE FROM THE PER- SPECTIVE OF PRIVATE TECHNICAL DANCE SCHOOL DIRECTORS IN RIO DE JANEIRO
}

\begin{abstract}
The objective of the present study is to verify the reasons for using the classical ballet technique for professional dancers under the view of directors of private technical dance schools in the city of Rio de Janeiro. For data collection, a semi-structured script was used and the sample consisted of four dance directors. The interviews were interpreted using the Discourse Analysis method proposed by Eni Orlandi. It was verified that the directors maintain the founding precepts of the technique in the formation of their dancers, but they put it in a new place that dialogues with other techniques and methods of the universe of the contemporary scenic dance.
\end{abstract}

Keywords: Dance. Ballet technique. Discourse analysis. Professional qualification. 


\section{SENTIDOS DEL USO DE LA TÉCNICA DE BALLET CLÁSICO BAJO LA PERS- PECTIVA DE DIRECTORES DE ESCUELAS TÉCNICAS PARTICULARES DE DANZA EN RÍO DE JANEIRO}

\section{Resumen}

Este estudio tiene el objetivo de identificar los sentidos del uso de la técnica de ballet clásico en el actual mercado de trabajo de danza profesional, desde la perspectiva de directores de escuelas técnicas particulares de danza de la ciudad de Río de Janeiro. Para la recogida de datos, se realizaron entrevistas semiestructuradas y la muestra fue compuesta por cuatro directores de danza. Los discursos fueron interpretados utilizando el método de análisis del discurso propuesto por Eni Orlandi. Se verificó que los directores conservan los principios fundadores de la técnica en la formación de sus bailarines, pero la situaron en un nuevo lugar, que dialoga con otras técnicas y métodos del universo de la danza escénica contemporánea.

Palabras clave: Danza. Técnica del ballet. Análisis del discurso. Formación profesional.

\section{Referências}

ACHCAR, D. Balé: uma arte. Rio de Janeiro: Ediouro, 1998.

ANSART, P. Ideologias, conflitos e poder. Tradução Aurea Weissenberg. Rio de Janeiro: Zahar, 1978.

ARAGÃO, V.; CAMINADA, E. Programa de ensino de ballet: uma proposição. Rio de Janeiro: UniverCidade, 2006.

BAUMAN, Z. Modernidade líquida. Tradução Plínio Dentzien. Rio de Janeiro: Zahar, 2001.

BOURCIER, P. História da dança no Ocidente. Tradução Marina Appenzeller. 2. ed. São Paulo: Martins Fontes, 2001.

BUARQUE, I. M. A. G. Memória dos corpos que dançam: a construção do campo profissional da dança na cidade do Rio de Janeiro (1970-1990). 2014. 273f. Dissertação (Mestrado em Memória Social) - Centro de Ciências Humanas, Universidade Federal do Rio de Janeiro, 2014.

DANTAS, M. De que são feitos os dançarinos de "aquilo..." Criação coreográfica e formação de intérpretes em dança contemporânea. Movimento, Porto Alegre, v. 11, n. 2, p. 31-57, maio/ago. 2005.

ELIAS, N.. O processo civilizador: formação do estado e civilização. Tradução Ruy Jungmann. Rio de Janeiro: Jorge Zahar, 1993. v.2.

FERREIRA, R. Para desequilibrar o balé: uma análise da constituição estética do balé. In: CONGRESSO INTERNACIONAL DE HISTÓRIA. Anais ... Jataí (GO), 2008.

GONÇALVES, T. Dança clássica no mundo contemporâneo? Paradoxos, dobras, extensões e invenções. In: ORG. INSTITUTO FESTIVAL DE DANÇA DE JOINVILLE. Seminários de 
dança de Joinville - A dança clássica: dobras e extensões. Joinville: Nova Letra, 2014. p. 5361.

HOMANS, J. Os anjos de Apolo: uma história do ballet. Tradução Jaime Araújo. Lisboa: Edições70, 2012.

MALANGA, E. B. Comunicação e balé. São Paulo: Ed Edima, 1985.

MAUSS, M. As técnicas corporais. In: W. B. de Almeida. São Paulo: EPU/EDUSP, 1974.

. Sociologia e antropologia. Tradução Mauro

MONTE, F.; NASCIMENTO, J. Reflexões sobre as mudanças no contexto histórico da dança do século XX e a dança na atualidade. Revista Digital, Buenos Aires, ano 13, n. 127, dez. 2008.

MOREIRA, Rui. Balé clássico: um dos métodos de formação e preparo de artistas de dança expressiva cênica na contemporaneidade. In: ORG. INSTITUTO FESTIVAL DE DANÇA DE JOINVILLE. Seminários de dança de Joinville - A dança clássica: dobras e extensões. Joinville: Nova Letra, 2014. p. 85-90.

OLIVEIRA, V. H. N. Corpo, dança e contexto: apontamentos sobre a técnica da dança em abordagens plenas. Dança, Salvador, v. 2, n. 1, p. 22-33, jan./jun. 2013.

ORLANDI, E. Análise de discurso: princípios e procedimentos. 11. ed. Campinas, SP: Pontes, 2013.

PEREIRA, R. A formação do balé brasileiro: nacionalismo e estilização. Rio de Janeiro: FGV, 2003.

Gruas Vaidosas. In: PEREIRA, R.; SOTER, S. Lições de dança 1. Rio de Janeiro: UniverCidade, 2006. p. 173-190.

PUOLI, G. O ballet no Brasil e a economia criativa: evolução histórica e perspectivas para o século XXI. 2010. 127f. Monografia (Bacharelado em Economia) - Curso de Graduação em Relações Internacionais da Faculdade de Economia da Fundação Armando Alvares Penteado, São Paulo, 2010.

SANTOS, C. A. P. Técnica clássica como ferramenta de criação: mediações possíveis. In: ORG. INSTITUTO FESTIVAL DE DANÇA DE JOINVILLE. Seminários de dança de Joinville - A dança clássica: dobras e extensões. Joinville: Nova Letra, 2014. p. 75-80.

SILVA, S.; MEDEIROS, C.; MARCHI, W. Habitus e prática de dança: uma análise sociológica. Motriz, Rio Claro, v. 18, n. 3, p. 465-475, jul./set. 2012.

SOUZA, V. S. O corpo que dança: história-social e hexis corporal no balé clássico. 2009. 165f. Dissertação (Mestrado em Artes) - Instituto de Artes, Universidade Estadual de Campinas, Campinas, 2009. 
ROCHA, T. Ballet sobre outras bases ou em que o tango pode ser bom para tudo. In: INSTITUTO FESTIVAL DE DANÇA DE JOINVILLE (Org.). Seminários de dança de Joinville - A dança clássica: dobras e extensões. Joinville: Nova Letra, 2014. p. 27-41.

TARASOV, N. I. Ballet technique for male dancer. Tradução Klassicheskii Tanets. New York: Doubleday \& Company, 1985.

TEIXEIRA, A.C. E. O surgimentos das companhias 2: uma pretensa "nova" forma de organização profissional de bailarinos que atingem idade em torno de 40 anos nas companhias públicas de dança brasileiras. Sala Preta, v.11, n. 11, 2011.

. Academia Real de Dança (1661) e Academia de Ópera em Música e Versos Franceses (1669): tradução das duas cartas oficiais deliberadas pelo Rei da França, Luís XIV, que institucionalizaram a arte da dança no século XVII. In: CONGRESSO NACIONAL DE PESQUISADORES EM DANÇA, 2. Anais... São Paulo: Comitê Memória e Devires em Linguagens de Dança, 2012. p. 1-9.

TORRES, R. G. A. Marcas híbridas em corpos que dançam a cena brasileira. In: CONGRESSO DA ASSOCIAÇÃO BRASILEIRA DE PESQUISA E PÓS-GRADUAÇÃO EM ARTES CÊNICAS, 5. Anais ... Belo Horizonte, 2008.

TRIVIÑOS, A. N. S. Introdução à pesquisa em ciências sociais: a pesquisa qualitativa em Educação. São Paulo: Ed. Atlas, 1987.

ZORN, Friedrich A. Grammar of the art of dancing. Boston: Dance Horizons, 1905.

Recebido em: 28/08/2016

Revisado em: 12/06/2017

Aprovado em: 28/08/2017

Endereço para correspondência:

hsdealmeida@uol.com.br

Heloisa Suzano Almeida

Universidade Candido Mendes

Rua da Assembleia, 10 - Centro

20011-901 - Rio de Janeiro - RJ 